\title{
IMPLEMENTATION OF IMPROVEMENTS IN THE CONDENSER OF THE AUTOMOTIVE CONDITIONING SYSTEM AIMING FOR GREATER THERMAL COMFORT
}

\author{
Jarielson Garcia Cruz ${ }^{1}$, Wandesson Santos Cruz ${ }^{2}$, Eduardo Rafael Barreda Del Campo ${ }^{3}$, Glaucielly \\ Garcia Cruz ${ }^{4}$, Jean da Silva de Abreu Silva ${ }^{5}$, Anderson Caldas de Oliveira ${ }^{6}$
}

\footnotetext{
1, 2, 5, 6 Discente em Engenharia Mecânica pelo Centro Universitário do Norte (UNINORTE). Manaus - AM.

${ }^{3}$ Doutor em Engenharia Mecânica pela Universidade Estadual de Campinas (UNICAMP). Professor do Centro Universítario do Norte (UNINORTE). Manaus - AM.

${ }^{4}$ Especialista em Métodos e Técnicas de Ensino pela Instituto Federal de Roraima (IFRR). Professora tutora a distancia do IFAM de Manaus. Roraima (RR).
}

Email: jarielsongarcia@ hotmail.com, wandesson93@gmail.com, eduardoserapio@yahoo.com.br, glaucy.mf.2007@gmail.com, jean.s.abreu@hotmail.com, anderson.oliiveira@hotmail.com.

Received: May 10 $10^{\text {th }}, 2019$

Accepted: May 22th 2019

Published: June 30th, 2019

Copyright (C2016 by authors and Institute of Technology Galileo of Amazon (ITEGAM). This work is licensed under the Creative Commons Attribution International License (CC BY 4.0). https://creativecommons.org/lice nses/by/4.0/

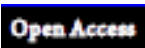

\begin{abstract}
The automotive air conditioning systems always used the concept of thermodynamic steam compression cycle. Even after a lot of research, some issues still remain unresolved, such as proper control of the inside temperature of the vehicle in warmer regions, such as in northern Brazil. Focusing on this issue, this article has proposed a new method to improve the control of internal temperature. The proposed method used the same concept of forced ventilation to improve heat exchange in the condenser, using an electro air blower and water from a reservoir. The proposed system was based on the theory of forced convection heat exchange. The results of the data presented showed that the survey was validated due to the drop of temperature of 3 degrees compared with the current system. In addition, the system pressure originally from 230 psi decreased to 150 psi.
\end{abstract}

Keywords: cooling, air conditioning, heat transfer, electric fan, temperature, forced convection.

\section{IMPLEMENTAÇÃO DE MELHORIAS NO CONDENSADOR DO SISTEMA DE CONDICIONAMENTO AUTOMOTIVO VISANDO MAIOR CONFORTO TÉRMICO}

\section{RESUMO}

Os sistemas de ar condicionado automotivo sempre utilizaram o conceito do ciclo de compressão de vapor termodinâmico. Mesmo depois de muitas pesquisas, algumas questões ainda permanecem sem solução, como o controle adequado da temperatura interna do veículo em regiões mais quentes, como no norte do Brasil. Focando nesta questão, este artigo propôs um novo método para melhorar o controle da temperatura interna. O método proposto usou o mesmo conceito de ventilação forçada para melhorar a troca de calor no condensador, usando um eletro ventilador de ar e água de um reservatório. O sistema proposto foi baseado na teoria de troca de calor por convecção forçada. Os resultados dos dados apresentados mostraram que a pesquisa foi validada devido à queda de temperatura de 3 graus se comparado com o sistema atual. Além disso, a pressão do sistema originalmente de 230 psi diminuiu para 150 psi.

Palavras-Chaves: refrigeração, ar condicionado automotivo, transferência de calor, eletroventilador, temperatura, convecção forçada. 


\section{INTRODUÇÃO}

Pela necessidade de retirar a umidade do ar de uma gráfica denominada Sacket \& Wilhelms no Brooklyn, Nova York, o engenheiro Willis Haviland [1] baseado em conceitos já fundamentados por outros estudiosos, criou o primeiro sistema mecânico de condicionamento de ar, colocando na pratica o que antes não passava de uma idealização, tornando possível o controle do clima em ambientes fechados.

Após a implementação desse sistema de condicionamento de ar em residências e empresas, Carrier expandiu sua visão para outro ramo implantando em 1930 esse sistema no primeiro veículo de transporte de passageiros, um trem da ferrovia B\&O. Com a empresa já consolidada na área, aliada à evolução tecnológica, após 169 anos desde a criação do primeiro veículo automóvel, ocorreu pela primeira fabricante Packard Motor Car Company à implementação em seus veículos desse sistema de ar condicionado em 1939, revolucionando, assim, a indústria automotiva em termos de conforto. Tendo como base de projeto o ciclo de refrigeração estudada na termodinâmica na área de engenharia mecânica [2].

Segundo [1] o sistema é composto de quatro principais componentes: compressor; condensador; válvula de expansão e evaporador, que nos veículos, dar-se a função de proporcionar conforto térmico aos passageiros [1].

Um dos maiores benefícios atualmente voltado para o conforto em se ter um automóvel em um pais tropical além de toda a estrutura mecânica é desfrutar de um sistema de ar condicionado bem dimensionado para todos os imprevistos que um clima tropical proporciona diariamente na região norte do País [2].

Uma das grandes problemáticas de um sistema de ar refrigerado para automóveis em países onde o clima ultrapassa os $35^{\circ}$ em sensação térmica no transito engarrafado é a diminuição na sua capacidade de refrigerar a parte interna do automóvel, isto devido à perda na troca de calor no condensador já que o veículo encontrasse parado em um transito muito lento sem o auxílio do vento proporcionado pelo deslocamento do veículo que ajuda no resfriamento do sistema [3].

Para se obter tal melhoria implantou-se um eletroventilador universal de 10 polegadas diretamente no condensador com auxílio de um esguicho de água com três saídas, pois o mesmo tem como função aumentar a troca de calor por convecção forçada. O presente trabalho teve como objetivo aperfeiçoar o sistema de refrigeração automotiva em horários críticos de congestionamento, além de descrever as melhorias do sistema implantado.

\section{FUNDAMENTAÇÃO TEÓRICA}

Segundo [6] "A refrigeração é o nome dado ao processo de remoção de calor de um meio, reduzindo sua temperatura e mantendo essa condição por meios mecânicos ou naturais". A refrigeração permite inúmeras aplicações, mas duas se destaca, a conservação de alimentos por congelamento e a climatização ou condicionamento de ar em residências e em automóveis [6].

$\mathrm{O}$ sistema de ar condicionado automotivo funciona com o ciclo de refrigeração convencional onde o mesmo necessita de trabalho mecânico para funcionar através de correia, transferida da energia gerada pela combustão interna do motor. A principal função do sistema é tornar ou proporcionar o maior conforto térmico no habitáculo do veículo, onde permite a substituição do ar quente pelo ar frio através do fluido refrigerante que passa pelo evaporador [7].

Segundo [1] o sistema é composto de quatro principais componentes: compressor; condensador; válvula de expansão e evaporador, que nos veículos, dar-se a função de proporcionar conforto térmico aos passageiros [1].

A figura 1 mostra os quatros componentes principais do sistema do ar condicionado automotivo, que são eles:

- Compressor: é o principal componente do sistema de ar condicionado, resposavel por comprimir o fluido refigerante que circula pelo sistema, sucçionando o gás de baixa pressão do evaporador e mandando-o para o condensador em alta pressão.

- Condensador: é o componente responsavel por receber o fluido refrigerante do compressor em alta pressão, e através do fluxo de vento do ventilador e do ambiente que passa entre suas aletas, fazer a troca de calor, permitido o resfriamento do fluido que segue como liquido de baixa pressão para a valvula de expansão.

- Válvula de expansão: é responsavel por restringir a passagem do fluido refrigerante que vem do condensador em forma de liquido a alta pressão, dininuindo consideravelmente a pressão e a temperatura do fluido que será enviado para o evaporador.

- Evaporador: é o componente que permite a troca de calor do ar do ambiente interno do veículo através do fluido refrigerante que vem da válvula de expansão em forma de gás a baixa pressão e temperatura, possibilitando a troca de calor quando o ar é submetido a passar por suas aletas ou colmeia, onde o fluido refrigerante retira o calor e umidade do ar e o manda de volta para o interior do veículo refrigerado e seco em um ciclo continuo.
CIRCUITO REFRIGERANTE COM VÁLVULA DE EXPANÇÃO VARIÁVEL

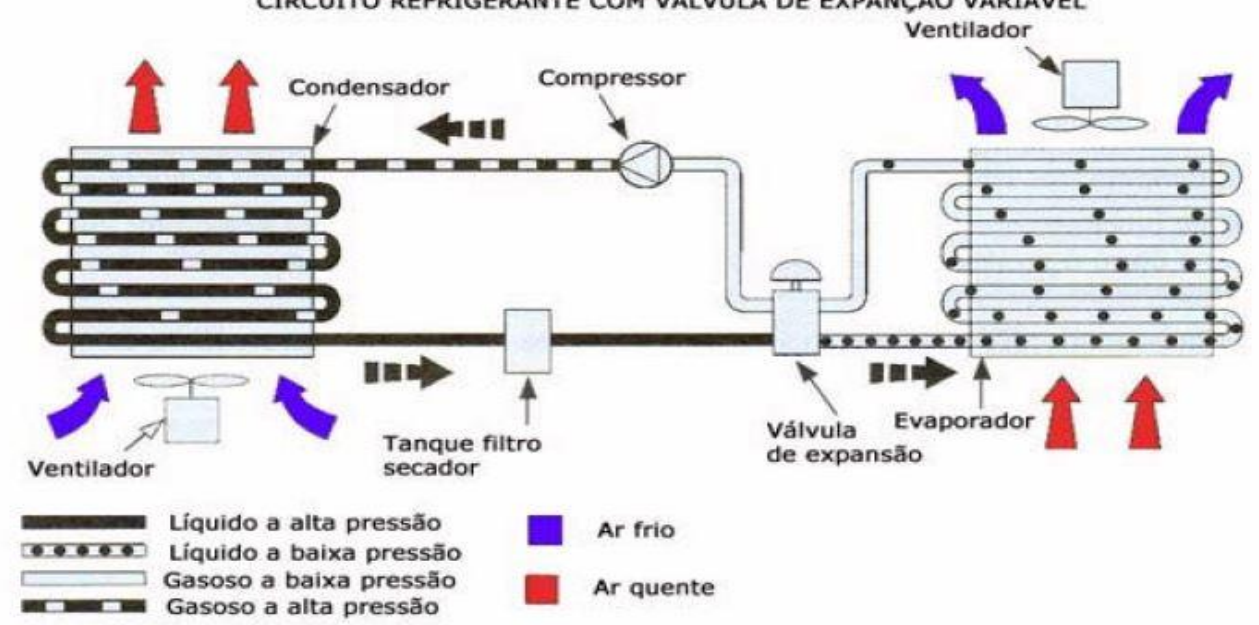

Figura 1: Componentes do ar condicionado automotivo. Fonte: k2 Ar condiconado automotivo, (2018). 
A figura 2, mostra desde os quartos principais componentes á todos os componentes compostos no sistema de ar condicionado veicular:

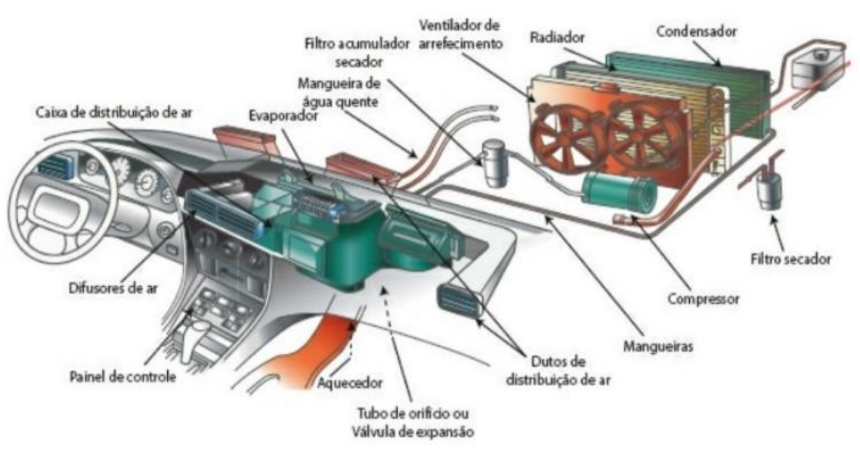

Figura 2: Componentes do sistema de ar condicionado. Fonte: [7].

O conceito de refrigerar só é possível graças ao estudo termodinâmico e de transferência de calor o qual foi base de raciocínio para o desenvolvimento desse projeto. O estudo da pesquisa, teve como princípio a transferência de calor no condensador do sistema de ar condicionado de automóveis, pois toda fonte de calor, se apresenta como um tipo de energia que pode ser transferida de um corpo para o outro quando há diferença de temperatura.

Segundo [8] "transferência de calor é energia térmica em transito devido a uma diferença de temperatura no espaço. Sempre que existir uma diferença de temperatura em um meio ou entre dois meios, haverá, necessariamente, transferência de calor" [8].

De acordo com [7] "a termodinâmica reconhece majoritariamente três modos distintos de transmissão de calor: condução, convecção e radiação", na transferência de calor [7].

Para descrever os fenômenos da transferência de calor com o novo sistema implantado por dispositivos de ventilação e jateamento de água para ajudar nesse processo, foi usado a transferência por convecção forçada que explica como ocorreu a melhoria após a implantação do mesmo no sistema.

Tendo em vista que a convecção é um atributo dos fluidos, líquidos e gases, Cutnell e Johnson, [9] diz que "convecção é um processo no qual se transporta calor de um lugar para outro pelo movimento macroscópico de um fluido". Para convecção forçada segundo [9] "quando a convecção natural não é suficiente para a transferência de calor usa-se a convecção forçada, como por exemplo, a ventilação de um motor de automóvel" [9].

Seguindo esse conceito de convecção forçada é que foi feito a adaptação no condensador do veículo para que através do jateamento de água do esguicho e pelo vento forçado através eletro ventilador diretamente no condensador houvesse uma maior troca de calor, melhorando o sistema de ar-condicionado e aumentando sua eficácia.

\section{MATERIAS E MÉTODOS}

\section{III.1 METODOLOGIA DA PESQUISA}

A pesquisa foi realizada a partir do ar condicionado do carro de marca Chevrolet modelo cobalt, o automóvel estava parado a céu aberto, com um monômetro analógico. Aferiu-se as pressões de baixa e alta temperatura para comparação, depois com um termômetro digital verificou-se a temperatura ambiente externa e interna do veículo.
A pesquisa baseou-se no ar condicionado do veículo com intuito de aumentar a troca de calor em horários críticos e de congestionamento, implantando-se um eletro-ventilador diretamente no condensador e um esguicho de água apontado para o mesmo.

O teste feito antes no sistema para aplicar os dispositivos na parte dianteira do condensador, constatou à temperatura ambiente de $33.6^{\circ} \mathrm{C}$, onde teve as pressões aferidas com valores em baixa pressão de 25 psi e na alta pressão de 230 psi no monômetro analógico, mostrado na figura 3. PSI, (medida de pressão) ou libra por polegada quadrada.

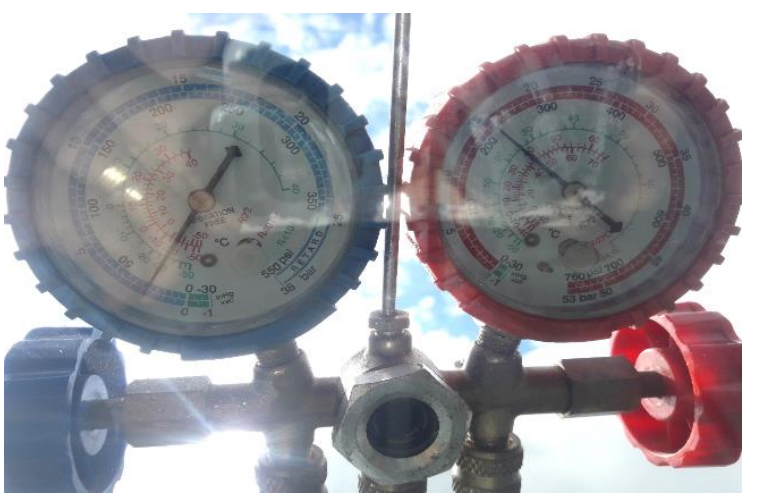

Figura 3: Monômetro Analógico de refrigeração. Fonte: Autores (2019).

Como o automóvel estava a céu aberto sua temperatura interna encontrava-se em $40^{\circ} \mathrm{C}$, com isso iniciou-se os testes o veículo ficou ligado por 10 minutos com o ar condicionado ligado na ventilação 3 para aferir a temperatura interna do veículo que se estabilizou-se em $18.8^{\circ} \mathrm{C}$, mostrado na figura 4 .

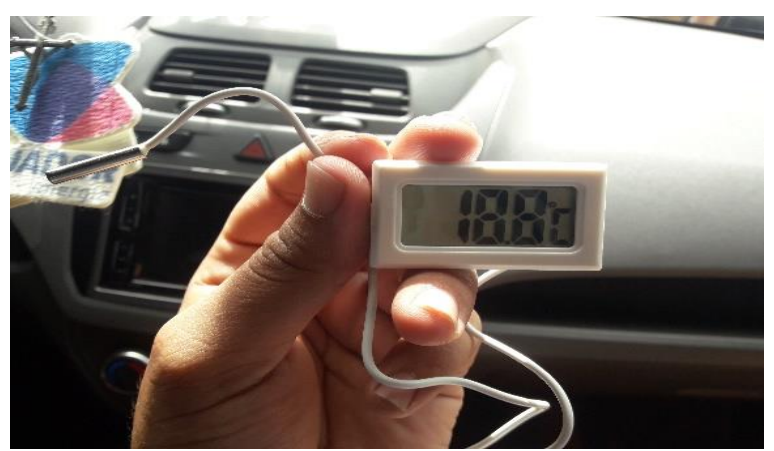

Figura 4: Termômetro digital temperatura interna estabilizada. Fonte: Autores, (2019)

Posteriormente ligamos o eletro-ventilador que ajudou a diminuir a pressão de alta e em seguida ligamos o esguicho por 30 segundos em uma sequência de 3 vezes no período de 10 minutos, onde a temperatura interna chegou a $15.4^{\circ} \mathrm{C}$, mostrado na figura 5 .

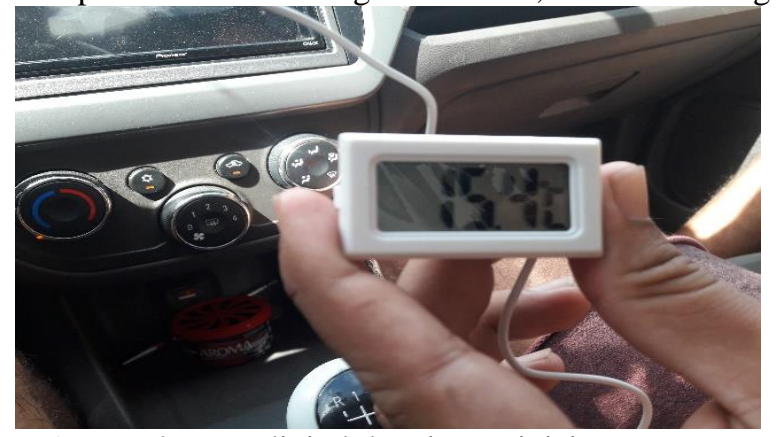

Figura 5: Termômetro digital depois que iniciou os testes com a implantação do sistema alternativo.

Fonte: Autores, (2019). 
Com o auxílio do esguicho de água as pressões de alta e baixa também mudaram, pois, a troca de calor por convecção aumentaram permitindo a pressão de alta chegar em 150 psi, mostrado na figura 6 .

Mostrando que a implantação do sistema proporcionou uma melhor troca de calor com o veículo parado.

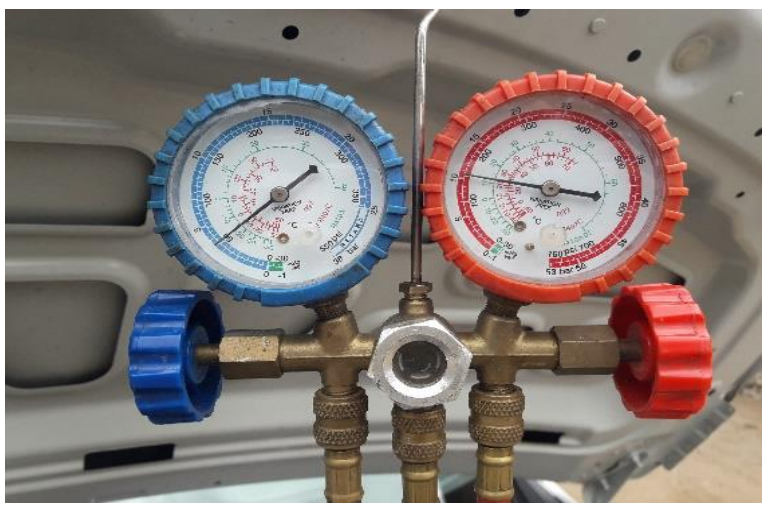

Figura 6: Monômetro Analógico de refrigeração após a implantação do sistema auxiliar.

Fonte: Autores, (2019).

Em seguida realizamos o mesmo experimento, porém sem está ligado o eletro e o esguicho, com o carro em movimento em uma estrada, o mesmo se encontrava em velocidade média de 77 $\mathrm{km} / \mathrm{h}$ com temperatura externa de $25^{\circ} \mathrm{C}$, mostrado na figura 7 .

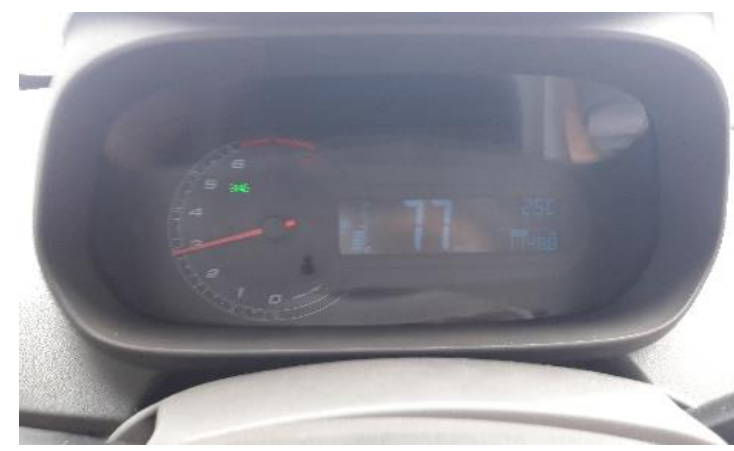

Figura 7: Painel do veículo modelo Cobalt.

Fonte: Autores, (2019).

O deslocamento do veículo permitiu uma troca de calor superior à do veículo parado por meio do vento, atingindo assim a temperatura interna de $14.5{ }^{\circ} \mathrm{C}$. Concluindo assim, que o sistema alternativo implantado cooperou satisfatoriamente na troca de calor variando $1^{\circ}$ grau de diferença do veículo parado para o veículo em movimento, mostrado na figura 8 .

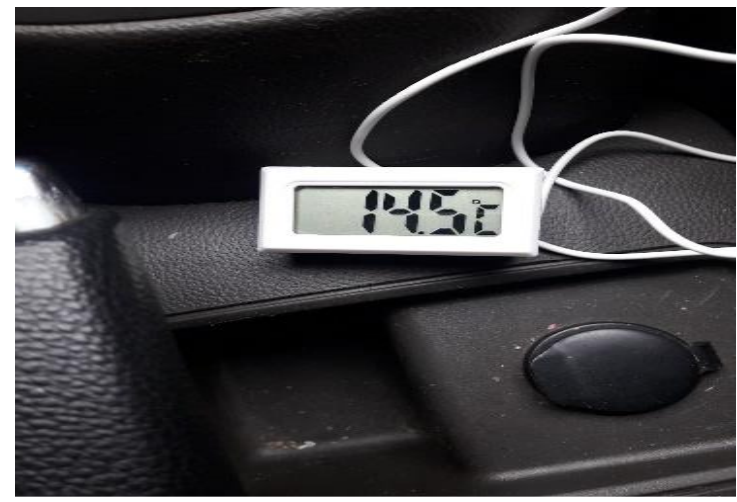

Figura 8: Termômetro digital, temperatura interna com veículo em movimento.

Fonte: Autores, (2019).

\section{III.2 MATERIAIS}

Os equipamentos necessários para melhoria no sistema de troca de calor do ar condicionado automotivo foram: um eletro ventilador universal de 10 polegadas de 12 voltes, mostrado na figura 9.

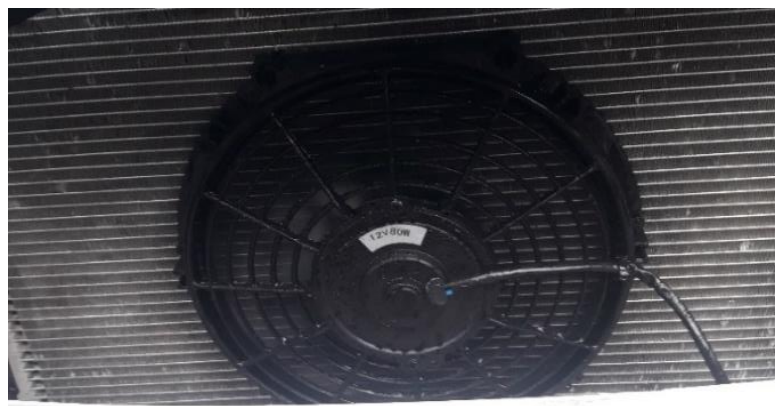

Figura:9 Eletro ventilador. Fonte: Autores, (2019).

Um esguicho de água universal de 3 saídas, o esguicho serve para ejetar a água no eletro ventilador que espalha no condensador diminuindo a temperatura e pressão no mesmo, mostrado na figura 10 .

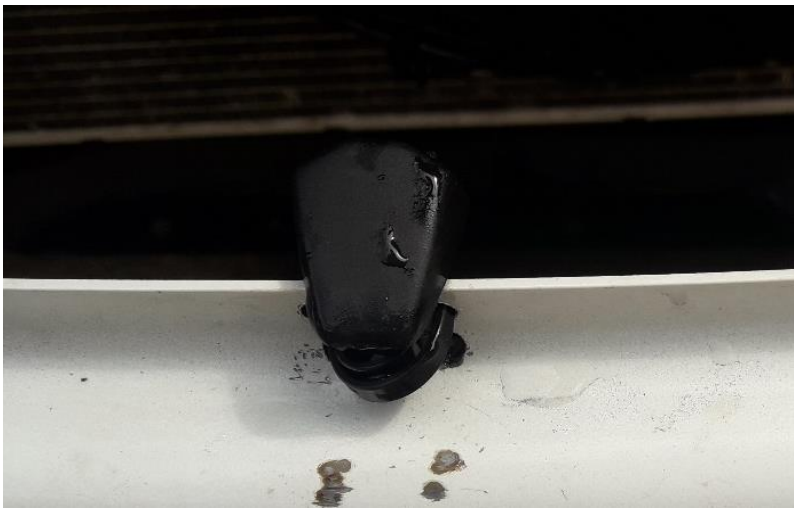

Figura:10 Esguicho de água.

Fonte: Autores, (2019)

Uma bomba de água universal que foi utilizada para transporta a água do reservatório até o esguicho, mostrado na figura 11.

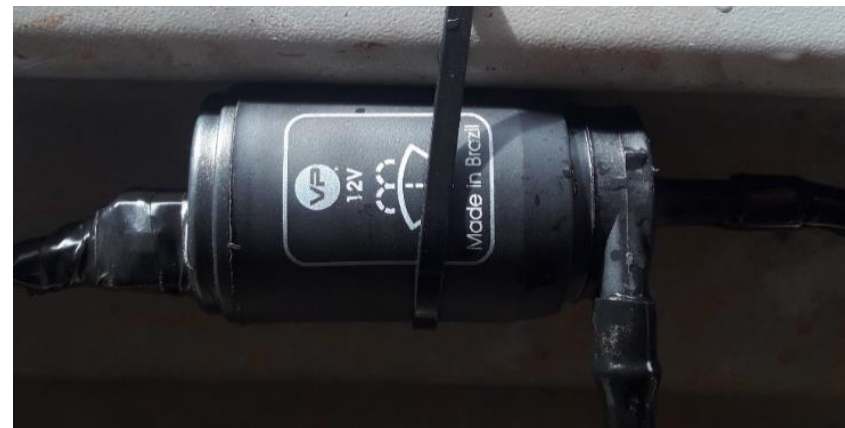

Figura 11: Bomba de água universal. Fonte: Autores, (2019)

Utilizou-se também um relé de 4 vias, manômetro analógico, termômetro digital e fios para fazer a instalação dos componentes e 8 abraçadeiras de plástico para fixar os componentes e $1 \mathrm{~m}$ de mangueira para ligar a bomba ao reservatório de água do veículo. 


\section{III.3 INSTALAÇÂO DOS DISPOSITIVOS}

- $\quad$ Primeiro tem que remover o para-choque dianteiro do veículo.

- Colocar o eletro ventilador no condensador com ajuda de quatro abraçadeiras de plástico.

- $\quad$ Colocar o esguicho na barra de ferro virado para frente do condensador.

- $\quad$ Prender a bomba de água universal com abraçadeira de plástico na barra de ferro onde foi colocado o esguicho.

- Fazer a instalação das mangueiras do reservatório do veículo até a bomba de água e da bomba para o esguicho.

- $\quad$ Fazer instalação elétrica para o eletro ventilado, no eletro é recomendado colocar um relé auxiliar, e depois fazer a da bomba com um botão de acionamento dentro do veículo.

- $\quad$ É recomendado você procurar um profissional na área de refrigeração automotiva ou elétrica automotiva, para fazer a instalação da melhoria.

\section{RESULTADOS E DISCURÇÕES}

O estudo realizado no decorrer da análise do sistema auxiliar implantado no ar condicionado do veículo, deu-se através de equipamentos de pressão (monômetro analógico) e temperatura (termômetro digital), onde obtivemos resultados satisfatórios mostrando que a melhoria implantada através de dispositivos no sistema de troca de calor no condensador para horários críticos de congestionamentos, satisfaz o objetivo proposto, visando atingir as necessidades dos passageiros, que poderão usufruir de um maior conforto térmico durante esse período.

Para demonstrar a eficácia desse sistema auxiliar de troca de calor, esboçamos o gráfico abaixo com os valores obtidos em testes, na figura 12 .

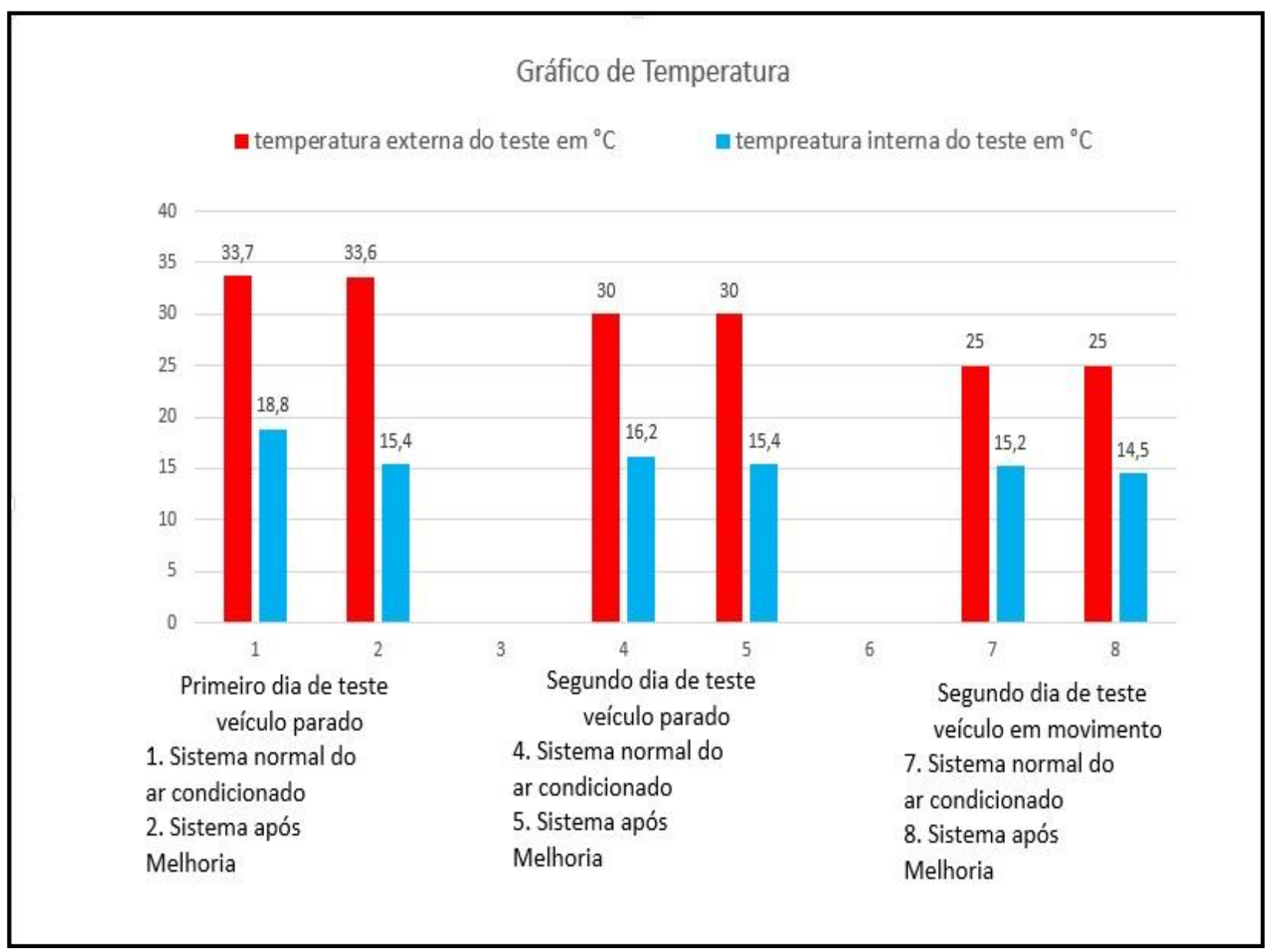

Figura 12: Gráfico de temperatura.

Fontes: Autores, (2019).

Analisando o gráfico da figura 12, através dos valores nele contido, antes e após a melhoria no sistema pode-se perceber que quanto maior for a temperatura externa maior será a queda de temperatura interna após o uso dos dispositivos implantados.

As colunas 1 e 4, representando os dois dias de testes, com veículo parado, mostram o sistema do ar condicionado do veículo ligado e estabilizado sem o uso dos dispositivos, já as colunas 2 e 5 mostram as informações após o uso dos dispositivos, demonstrando assim, que com a melhoria na troca de calor no condensador por esses dispositivos possibilitou a diminuição de 3,4 graus no primeiro dia de teste mais quente e 0,8 graus no segundo dia de teste mais frio.

As colunas 7 e 8 , representam os dados coletados com o veículo em movimento em uma BR. A coluna 7 com o sistema ligado e estabilizado sem o uso dos dispositivos e depois na coluna 8 com os dispositivos em funcionamento, tendo uma diminuição de 0,7 graus.

Os dados demostram a melhoria com efeitos positivos em temperatura mais elevadas como acontece em horários críticos de congestionamento onde se encontra o real objetivo do projeto. 


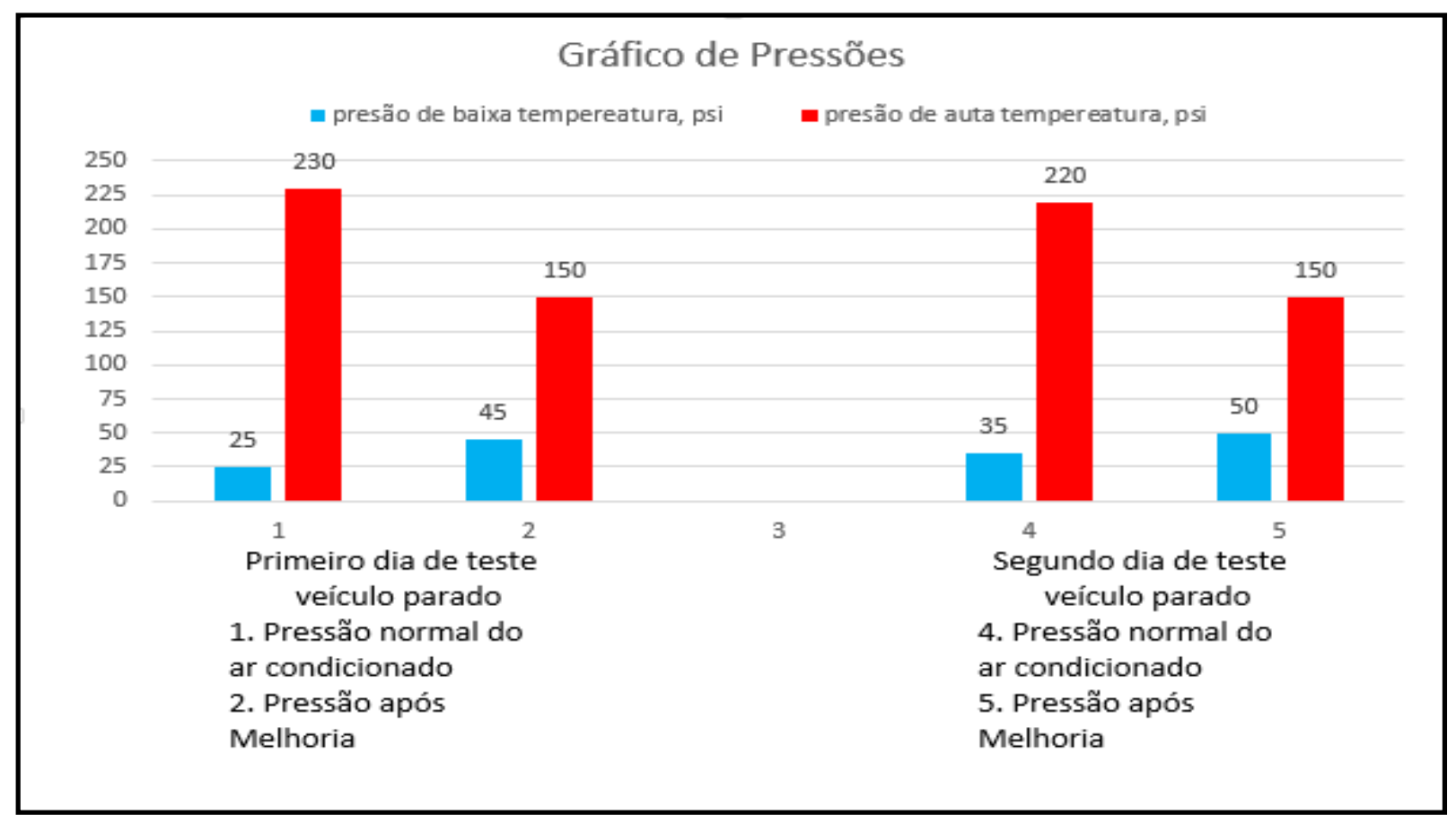

Figura 13: Gráfico de Pressões.

Fontes: Autores, (2019).

No gráfico 13 (de pressões) a coluna 1 e 4 mostram as pressões de alta e baixa temperatura com o sistema do ar condicionado normal sem o uso dos dispositivos, já a coluna 2 e 5 mostra o sistema com os dispositivos de melhoria funcionando e demonstrando resultados positivos.

Analisando o gráfico a partir dos dados obtidos, fica visível que com a adaptação feita no sistema á uma melhora significativa nas pressões de temperaturas, reduzindo a pressão de alta em 80 Psi, e aumentando a pressão de baixa em 20 Psi, diminuindo o esforço do compressor na hora de comprimir o gás refrigerante, permitindo que o sistema trabalhe em um nível confortável, aumentando sua eficiência de funcionamento e garantindo a refrigeração necessária proposta no dimensionamento do projeto desse sistema que não garantia conforto térmico nessas condições para nosso tipo de clima mais quente já que não foram dimensionados levando em consideração esse fator, demostrado na figura 13 .

\section{CONCLUSÃO}

A partir dos dados coletados e apresentados nesse artigo, é visível que grande parte da problemática causada pelo clima quente da zona tropical na hora de se trocar calor no condensador do veículo é corrigido pelo novo sistema auxiliar que facilita a troca sem a necessidade do compressor trabalhar incansavelmente e sem a necessidade do fluxo de ar promovido pelo movimento do carro.

Com isso, a abordagem de melhoria do sistema de refrigeração em automóveis por meio de dispositivos de ventilação e irrigação de água direto no condensador é viável e eficaz, facilitando a troca de calor na hora de resfriar o ambiente interno do veículo em condições climáticas mais elevadas com um fluxo de ar externo mais limitado pelas paradas do veículo em congestionamento em situações críticas de funcionamento destes sistemas.

Recomendamos para pesquisas futuras baseado nesse conceito, um direcionamento voltado para a diminuição do consumo de combustível após a aplicação desse sistema auxiliar que também se mostrou benéfico nesse quesito.

\section{REFERÊNCIAS}

[1] Kaynakli, O.; Horuz, I. An experimental analysis of Automotive Air Conditioning System. International Community of Heat and Mass Transfer, Vol. 30, USA: Elsevier Science, 2003.

[2] Creder, Hélio. Instalação de Ar condicionado. $6^{\mathbf{a}}$ ed. Rio de Janeiro: LTC, 2004, 318p.

[3] Santos, Eduardo Oliveira dos. Dimensionamento e avaliação do ciclo de refrigeração de sistemas de climatização automotivo, São Paulo, 1-131, 2005.

[4] Itao, Danilo Carreira. Estudo de um sistema alternativo de ar condicionado automotivo baseado na aplicação de tubos de vórtice utilizando o conceito de regeneração energética, São Paulo, 1-115, 2005.

[5] Beatrice, Luiz Henrique Maimone. Sistema de climatização baseado no ciclo Brayton, São Paulo, 1-10.

[6] Silva, Jesué Graciliano da. Introdução à tecnologia da refrigeração e da climatização. $2^{a}$ ed. São Paulo: ARTLIBER, 2003,263p.

[7] Macedo, F. G.; Filho, G. A.; Kuroda, M. Climatização automotiva. ed. São Paulo: Senai-SP, 2016.

[8] Incropera, F., Dewitt, D., Bergman, T., et al. Fundamentos de Transferência de calor e de Massa: $6^{a}$ ed. Rio de Janeiro: LTC, 2008.

[9] Silva, V. G., Zômpero, A. F., Laburú, C. L., Utililização de materiais potencialmente significativos sobre transferência de calor para alunos do ensino médio, Paraná, 1-17, 2014. 